\title{
Ler Interfaces: avaliação das interfaces gráficas de aplicativos de literatura para a infância
}

Douglas Menegazzi

Douglas.menegazzi@ufsc.br

Universidade Federal de Santa Catarina (UFSC), Florianópolis - SC, Brasil

\section{RESUMO}

Apesar da popularização dos dispositivos de interação móvel (DIMs), como tablets $e$ smartphones, e aplicativos (apps) no cotidiano familiar e escolar das crianças, há ainda grande resistência de pais e educadores na seleção e uso de livros infantis digitais devido à falta de conhecimentos e de familiaridade na mediação e interação com interfaces digitais associada à - ou consequente da - abundância de aplicativos comerciais problemáticos, com falhas no design de interação. Tendo como base principalmente teorias e estudos de literatura para crianças no âmbito digital, e dando continuidade a estudos prévios pelo viés do Design de Interação, a pesquisa apresentada neste artigo tem como objetivo avaliar interfaces gráficas de apps literários para crianças. Assim, neste artigo é realizada a análise descritiva de três apps comerciais seguida de observação de leitura mediada destes com seis díades de pais e filhos entre 6 e 8 anos de idade. Como resultados, são identificados êxitos e inconsistências no design das interfaces gráficas dos apps, o que pode contribuir prontamente com designers, editores e também servir a pesquisadores, pais e educadores pra uma seleção e mediação literária mais criteriosa e consistente no que se refere a livros infantis digitais.

PALAVRAS-CHAVE: Livro infantil digital. E-book infantil. Design de interação. Leitura mediada. 


\section{INTRODUÇÃO}

Diferente das primeiras gerações de livros infantis eletrônicos, que eram essencialmente digitalizações de livros impressos, o formato app surge como um texto "nativo-digital" (AL-YAQOUT; NIKOLAJEVA, 2015), que tem por característica a multimodalidade (MORGAN, 2013), pois "combina convenções usadas em livros ilustrados impressos, design de jogos e filmes animados [...] com conteúdo interativo e rico em multimídia" (SARGEANT, 2015, p. 461). Não por acaso, livros infantis de formato aplicativo são comumente confundidos com jogos digitais ou filmes animados, mas na verdade, para Al-Yaqout e Nikolajeva (2015), localizamse na fronteira, como "textos híbridos" com os quais é cada vez mais frequente que os leitores mais jovens tenham seu primeiro contato com a literatura.

A natureza interativa dos aplicativos é entrelaçada com a multimídia, mas difere dos livros impressos, nos quais a interação está relacionada aos recursos manipulativos, como abas, alavancas e texturas diferentes que incentivam os leitores a se envolver com a história por meio da materialidade do livro (KUCIRKOVA, 2017). No digital, a interação se apresenta na forma de hotspots, áreas interativas da interface, que são operacionalizadas para acionar conteúdos narrativos e respostas do sistema pelo toque na tela touch screen por meio de códigos de gestos do leitor (Ibid).

Estas alterações provocadas pela convergência entre a literatura para infância e a tecnologia têm ocasionado uma "experiência híbrida de leitura" (HØYRUP, 2017) que gera não apenas novas oportunidades de multiletramento (MORGAN, 2013), mas impasses e desafios à adesão e seleção de apps por mediadores no ambiente familiar e escolar (LIMA, 2019). O que se deve, segundo Lima (2019): ao preconceito e falta de familiaridade de pais e educadores com artefatos digitais; a desvalorização da narrativa digital em relação à literatura convencional impressa; e, a diversificação de obras que mesclam a tecnologia e outras formas de arte originando novas propostas de experiências estéticas híbridas que, devido a sua complexidade, ainda não dispõem de critérios consolidados para sua produção e seleção. Além disso, grande parte dos apps comerciais é projetada com o objetivo de entretenimento para manter as crianças ocupadas e, assim, a necessidade de participação de adultos tem sido cada vez mais anulada (FOLLMER et al., 2012). Ainda mais problemático quando os produtores incluem grande quantidade de interações e jogos para tornar os apps mais comerciais às crianças, o que provoca o efeito "eye-candy" ("olho doce"), e tende a transformar a atividade em um jogo em vez de uma experiência de leitura (BUS; TAKACKS; KEGEL, 2015, p. 192).

Mesmo que a qualidade de aplicativos literários dependa em grande parte da interdependência dos recursos multimídia e de interação para criar uma experiência de leitura unificada (CAHILL; MCGILL-FRANZEN, 2013) e congruente à narrativa literária (KUCIRKOVA, 2017), a interface gráfica continua sendo, como no livro infantil impresso, o principal ponto de interação do leitor (MENEGAZZI, 2018). Portanto, para que as crianças se beneficiem de livros digitais é importante que simultaneamente compreendam como utilizá-los e isso depende da qualidade de affordances (KAMYSZ; WICHROWSKI, 2014, BUS; TAKACS; KEGEL, 2015), propriedades que permitem ao leitor reconhecer e saber como interagir com as áreas interativas dos apps. Isso, porque a linguagem visual dos aplicativos configura-se simultaneamente para duas finalidades, na construção da narrativa literária ou para usabilidade (MENEGAZZI; PADOVANI, 2017). Assim, o sucesso dos 
apps literários depende "criticamente de uma variedade de fatores pedagógicos e de design, bem como da maturidade das funções executivas e habilidades de compreensão que a criança possui ${ }^{1 "}$ (BUS; TAKACS, KEGEL; 2015, p. 89, tradução nossa).

Neste contexto, este artigo quer avaliar o design das interfaces gráficas de apps de literatura para a infância no contexto da leitura mediada. Para isso, é realizado o mapeamento e análise das interfaces gráficas de uma amostra de apps comerciais, seguido da observação destas com díades de pais e filhos. Este estudo se concentra apenas nas interfaces de páginas literárias, internas, dos apps. Páginas de jogos e de atividades pedagógicas extras não são contempladas devido à necessidade de outras abordagens analíticas.

\section{O MAPA DAS INTERFACES GRÁFICAS E SELEÇÃO DA AMOSTRA}

Existe na literatura científica diferentes referências e modelos para análise de interfaces de aplicativos literários para a infância como, por exemplo, abordagens centradas na narrativa interativa (TEIXEIRA; GONÇALVES, 2015), estudos comparativos entre propriedades gráficas de livros impressos e digitais com a intenção de mitigar alterações e, assim, orientar mediadores acostumados com o formato de papel (JAVORSKY; TRAININ, 2014, AL-YAQOUT; NIKOLAJEVA, 2015). E, também, há esforços que apontam direções para usufruir da "experiência (poli)estética" de apps a partir na mediação no ambiente doméstico (CARDOSO; FREDERICO, 2019).

Contudo, nesta pesquisa o autor dá continuidade e, assim, aplica e aperfeiçoa uma ferramenta que vem desenvolvendo pelo viés do design de interação. Por isso, esta análise utiliza o Mapa das Interfaces Multimodais e Multimídias de Livros Infantis para DIMs, proposto inicialmente como um panorama revisado da literatura científica entre 2010 e 2017 (MENEGAZZI, 2018). Subsequentemente ampliado e corrigido, por meio de estudos descritivos com apps comerciais (MENEGAZZI; PADOVANI; SYLLA, 2018a), por análises multimodais de leitura mediada (MENEGAZZI, 2019) e por revisão bibliográfica integrativa (MENEGAZZI, 2020), configurando-se como um mapa que pode orientar análises (MENEGAZZI; PADOVANI; SYLLA, 2018b) e o próprio design de interação de aplicativos literários para crianças (MENEGAZZI; SYLLA; PADOVANI, 2020). Devido ao pouco espaço deste artigo e sua proposta específica, são apresentadas aqui as atualizações do mapa exclusivamente circunscritas à interface gráfica.

Nesta versão mais recente do mapa (fig. 1) foi realçada a importância da interface gráfica, no centro, em relação às demais - tátil e sonora -, e destacada a interdependência multimodal entre elas, por meio de linhas conectoras. Por exemplo, a multimídia audiovisual está mapeada na conexão entre as interfaces gráfica e sonora, como uma mídia híbrida que pode aparecer nos apps na forma de: animações e vídeos com finalidade narrativa, como efeitos de transição entre páginas (SERAFINI et al., 2016); como pistas que indicam as áreas interativas (KAMYSZ; WICHROWSKI, 2014); para a instrução de como leitor deve interagir com o dispositivo (YUILL; MARTIN, 2016) - chacoalhar, virar, mover etc.; ou, ainda, na forma de feedbacks que orientam a interação e o aprendizado (KAO et al., 2016). 
No âmbito das mídias gráficas verbais, o mapa diferencia texto narrativo dos descritivos de usabilidade e dos textos instrucionais (MENEGAZZI; PADOVANI, 2017). Enquanto considera as mídias não-verbais estáticas sendo compostas, como na primeira versão (MENEGAZZI, 2018), de ilustrações, fotografias, botões e ícones de navegação, agora contabiliza também as pistas de interação e esquemas instrucionais (KAO et al., 2016). Conforme o diagrama (fig. 2), a interface gráfica, quando integrada com as demais, pode proporcionar atividades virtualmente imersivas (SARGEANT, 2015), como jogos digitais e, em resposta às interações do leitor com os sensores de movimento - giroscópio - e velocidade - acelerômetro dos DIMs, oportunizar acesso de conteúdos por geolocalização ou movimentos $360^{\circ}$ (KUCIRKOVA, 2017), recursos hoje comuns em jogos de realidade virtual e aumentada como, por exemplo, Pokémon Go.

Figura 1: Mapa das Interfaces Multimodais e Multimídias de Livros Infantis para DIMs.

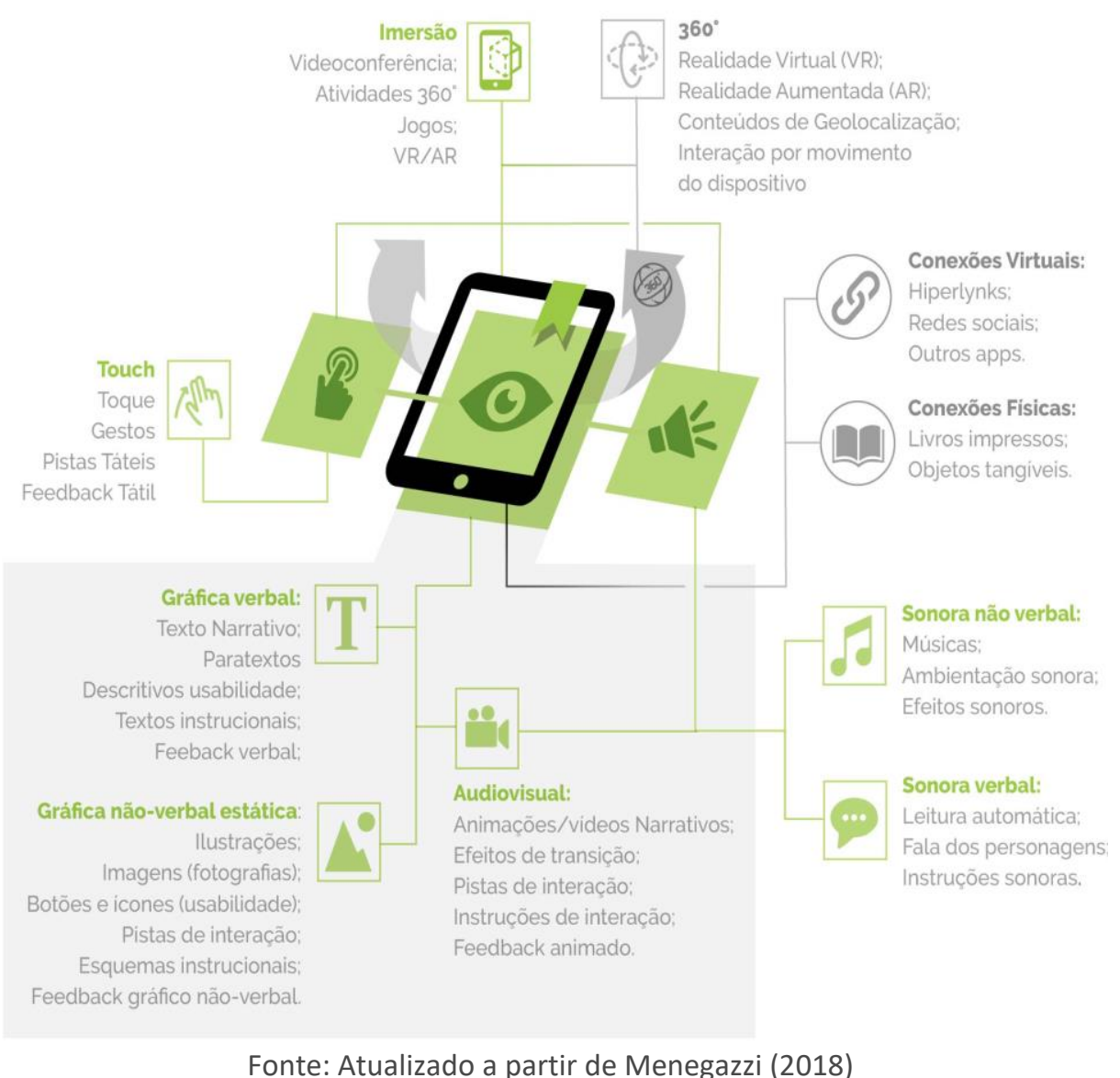

Para a análise por meio da ferramenta acima mencionada, os aplicativos de histórias infantis foram selecionados pela disponibilidade do idioma em português, compatibilidade com a faixa etária entre 6 e 8 anos e visando diferentes interfaces gráficas e hotspots que permitam variação para a análise. Da lista do Prêmio Jabuti (2016) foi selecionado (a) Quanto Bumbum! (2016), um livro com narrativa audiovisual. O app (b) Marina está do Contra (2017) foi selecionado pela interface diferenciada, integrada a sensores de movimento do DIM. O aplicativo (c) Macaco 
de Chapéu (2014), por ser um dos mais comercializados na App Store. A imagem a seguir (fig.2) apresenta a página inicial de cada um dos três apps selecionados.

Figura 2: Páginas internas dos apps, na ordem: a) Quanto Bumbum! (2016); (b) Marina está do Contra (2017); c) Macaco de Chapéu (2014).
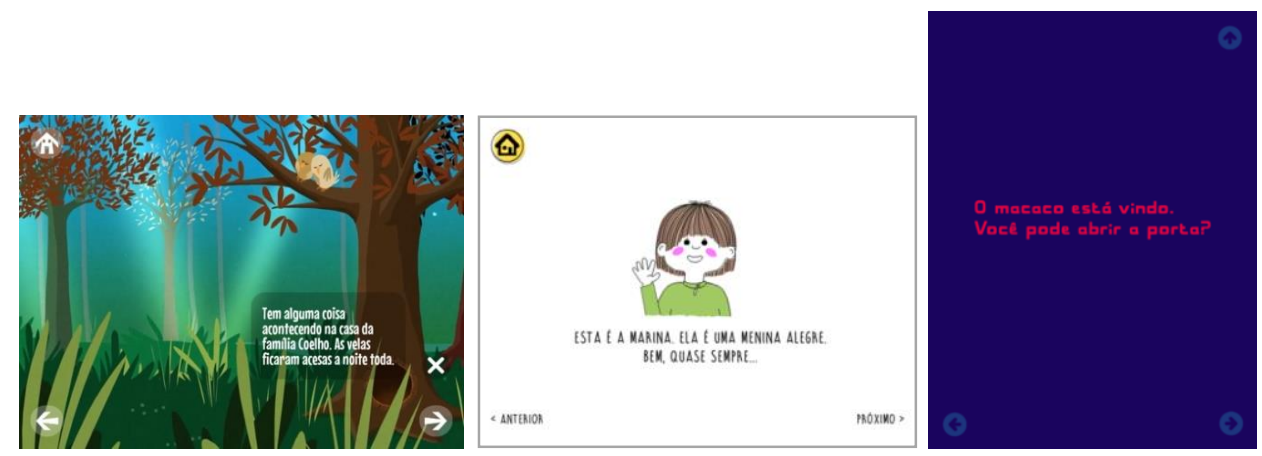

Fonte: (CTodos os direitos reservados às editoras.

\section{O MAPEAMENTO DAS INTERFACES GRÁFICAS DE APPS DE LITERATURA PARA CRIANÇAS}

Analisados os três apps selecionados (fig. 2) por meio do Mapa das Interfaces Multimodais e Multimídias de Livros Infantis para DIMs (fig. 1), foi verificado que apresentam suas narrativas literárias na convergência entre texto verbal, ilustrações e animações interativas, contudo por arranjos diferenciados (conforme é possível perceber na fig.1).

O app Quanto Bumbum! valoriza a narrativa preponderantemente audiovisual, pois cada página apresenta uma animação que, após habilitada pela interação do leitor, desenvolve-se como um filme animado sobre o qual aparece o texto verbal em caixas que podem ser "fechadas". Já Macaco de Chapéu traz os textos verbais em páginas intercaladas e separadas daquelas com ilustrações e animações interativas, o que demonstra maior valorização e cuidado com a leitura verbal da criança. O app Marina está do Contra é o que mais integra simultaneamente o texto verbal com ilustrações e animações interativas na mesma página.

Botões de usabilidade na forma de ícones (fig. 3) são outra característica comum a todos os aplicativos, enquanto setas para a navegação entre páginas sempre localizados nos cantos inferiores da interface e, para dar acesso aos menus da página inicial, na forma de um botão "home" em um dos cantos superiores (veja a localização dos botões na fig.2). Entretanto, os botões de navegação entre páginas no app Marina está do Contra acompanham descritivos verbais "anterior" e "próxima". Já Macaco de Chapéu, diferencia-se ao propor também uma seta para o botão "home", neste caso apontada para cima. Como mencionado, Quanto Bumbum! é o único app que traz um botão extra para desabilitar/habilitar o texto verbal, permitindo modificar o modo de leitura. 
Figura 3: Conjunto de botões nas páginas internas dos apps, na ordem, Quanto Bumbum! (2016), Marina está do Contra (2017), Macaco de Chapéu (2014).

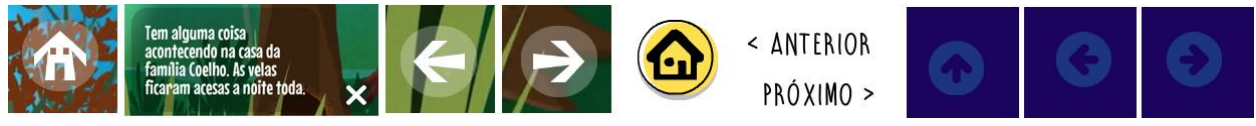

Fonte: (C) Todos os direitos reservados às editoras.

Os três apps trazem ilustrações e animações interativas, seja em um nível mais dinâmico e gamificado, como é o caso de Macaco de Chapéu que permite o leitor "ligar" para o Macaco, ou de maneira mais pontual como, por exemplo, para mudar os penteados de Marina em Marina está do Contra, ou apenas para habilitar a sequência de filmes animados em Quanto Bumbum!. Mas, apenas estes dois últimos trazem pistas gráficas animadas de interação, na forma de círculos pulsando (fig. 4 - esquerda) ou como um ícone de uma mão sugerindo áreas interativas (fig. 4 - direita).

Figura 4: Pistas interativas em Quanto Bumbum! (esquerda) e em Marina está do Contra (direita).
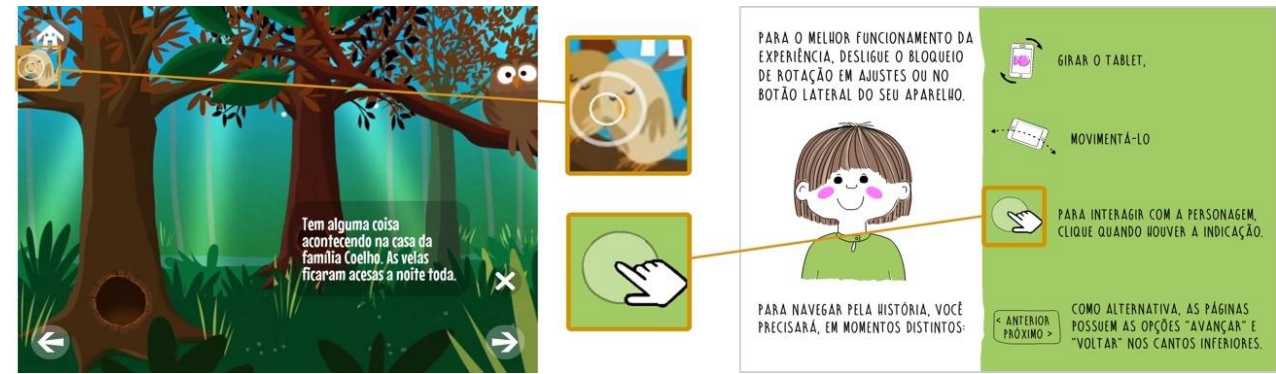

Fonte: (C) Todos os direitos reservados às editoras.

Destoante dos demais, Marina está do Contra demanda a interação pelo sensor de movimento - giroscópio - do dispositivo tablet, pois toda vez que os leitores avançam para a página seguinte, esta é carregada "de ponta-cabeça", o que implica que o leitor precise virar horizontalmente o tablet para conseguir ler, um recurso interativo projetado para reforçar a história de uma menina que contraria o modo tradicional de realizar ações cotidianas. Por esse motivo, é o único aplicativo a apresentar uma página de instrução (fig. 4 - direita) e também esquemas instrucionais animados durante as páginas internas para instruir o leitor a "girar o tablet" e "movimentá-lo". Já em O Macaco de Chapéu, é possível identificar a presença de instruções verbais de onde e como interagir com hotspots da história, mas de modo integrado ao texto narrativo, por exemplo em uma das páginas o convite ao leitor: "você pode bater na mão do Macaco?".

Em apenas O Macaco de Chapéu foi possível identificar, mesmo que sutilmente, a ocorrência de feedback animado quando, após o leitor tocar em uma das setas de navegação entre páginas, estas dão lugar ao ícone "carregando", confirmando visualmente ao leitor o comando executado.

A análise orientada pelo Mapa das Interfaces Multimodais e Multimídias de Livros Infantis para DIMs (fig. 1) permitiu mapear e compreender quais elementos 
compõem as interfaces gráficas dos três aplicativos e, por meio de uma síntese descritiva (quadro 1), comparar variações e similaridades entre elas.

Quadro 1: Mapeamento das interfaces gráficas dos apps.

\begin{tabular}{|c|c|c|c|}
\hline $\begin{array}{l}\text { Elemento da } \\
\text { Interface Gráfica }\end{array}$ & $\begin{array}{l}\text { Aplicativo A } \\
\text { Quanto Bumbum }\end{array}$ & $\begin{array}{l}\text { Aplicativo B } \\
\text { Marina está do Contra }\end{array}$ & $\begin{array}{l}\text { Aplicativo C } \\
\text { Macaco de Chapéu }\end{array}$ \\
\hline \multicolumn{4}{|l|}{ Texto Gráfico Verbal } \\
\hline Texto Narrativo & $\begin{array}{l}\text { Em todas as páginas sobre as } \\
\text { ilustrações/animações, } \\
\text { possível de ser "desabilitado". }\end{array}$ & $\begin{array}{l}\text { Em todas as páginas } \\
\text { acompanhado de } \\
\text { ilustrações/animações. }\end{array}$ & $\begin{array}{l}\text { Em páginas isoladas, } \\
\text { precedente às páginas } \\
\text { com ilustrações e } \\
\text { animações. }\end{array}$ \\
\hline $\begin{array}{l}\text { Descritivos de } \\
\text { usabilidade }\end{array}$ & Não há. & $\begin{array}{l}\text { Descritivo dos botões de } \\
\text { navegação entre } \\
\text { páginas. }\end{array}$ & Não há. \\
\hline Textos instrucionais & Não há. & Em uma página inicial. & $\begin{array}{l}\text { Na forma de texto } \\
\text { narrativo. }\end{array}$ \\
\hline \multicolumn{4}{|c|}{ Gráfico Não Verbal Estática } \\
\hline Ilustrações & Cenários. & Cenários. & Cenários. \\
\hline Botões e ícones & $\begin{array}{l}\text { Setas para navegação entre } \\
\text { páginas e ícone "casa" para } \\
\text { voltar à página home (menus). }\end{array}$ & Idem app A. & $\begin{array}{l}\text { Setas de navegação entre } \\
\text { páginas e seta (para cima) } \\
\text { para retornar à } \\
\text { homepage. }\end{array}$ \\
\hline \multicolumn{4}{|l|}{ Audiovisual } \\
\hline $\begin{array}{l}\text { Animações } \\
\text { narrativas }\end{array}$ & Personagens animados & Personagem. & Personagem \\
\hline Efeitos de transição & "tela preta" & $\begin{array}{l}\text { Inversão horizontal de } \\
\text { cada página do livro. }\end{array}$ & $\begin{array}{l}\text { "Corte seco" entre } \\
\text { páginas. }\end{array}$ \\
\hline Pistas de interação & Círculos "pulsantes". & $\begin{array}{l}\text { "Mãozinha" como um } \\
\text { cursor. }\end{array}$ & $\begin{array}{l}\text { Personagem aponta para } \\
\text { botão de iniciar leitura. }\end{array}$ \\
\hline Instruções animadas & Círculos "pulsantes". & $\begin{array}{l}\text { Na página instrucional e } \\
\text { durante todas as } \\
\text { páginas }\end{array}$ & Não há. \\
\hline $\begin{array}{l}\text { Feedback } \\
\text { audiovisual }\end{array}$ & Não há. & Não há. & $\begin{array}{l}\text { O botão de navegação } \\
\text { vira o ícone "carregando". }\end{array}$ \\
\hline
\end{tabular}

Fonte: Autoria própria (2020).

\section{OBSERVAÇÃO DE LEITURAS MEDIADAS: PARTICIPANTES E PROCEDIMENTOS}

Para avaliar a eficácia das interfaces gráficas dos apps para os leitores, foram realizadas sessões de leitura mediada com seis díades, cada uma composta por uma criança entre 6 e 8 anos acompanhada de um dos pais. Nesta idade, limite para alfabetização e letramento, apesar das crianças já possuírem certa independência para a leitura, ainda necessitam de suporte (PNAIC, 2017). Os participantes foram selecionados em uma escola pública portuguesa, dos quais duas famílias eram de brasileiros residentes. As sessões, realizadas entre maio e julho de 2018, ocorreram na Biblioteca da Escola após as aulas, quando os pais buscavam os filhos. Cada uma das seis duplas realizou a leitura dos três apps em dias diferentes (fig. 5), totalizando dezoito sessões por um sistema de alternância da ordem de leitura dos apps, para diminuir inconsistências de dados entre o primeiro e último lidos. Este arranjo se deve à hipótese de que os participantes adquiririam familiaridade com o dispositivo de leitura (iPad) e com as interfaces digitais conforme progredissem as sessões. O diretor da escola e os pais autorizaram por escrito a pesquisa, coleta e publicação de dados e imagens. 
Figura 5: Frames das gravações de vídeo das díades lendo apps.
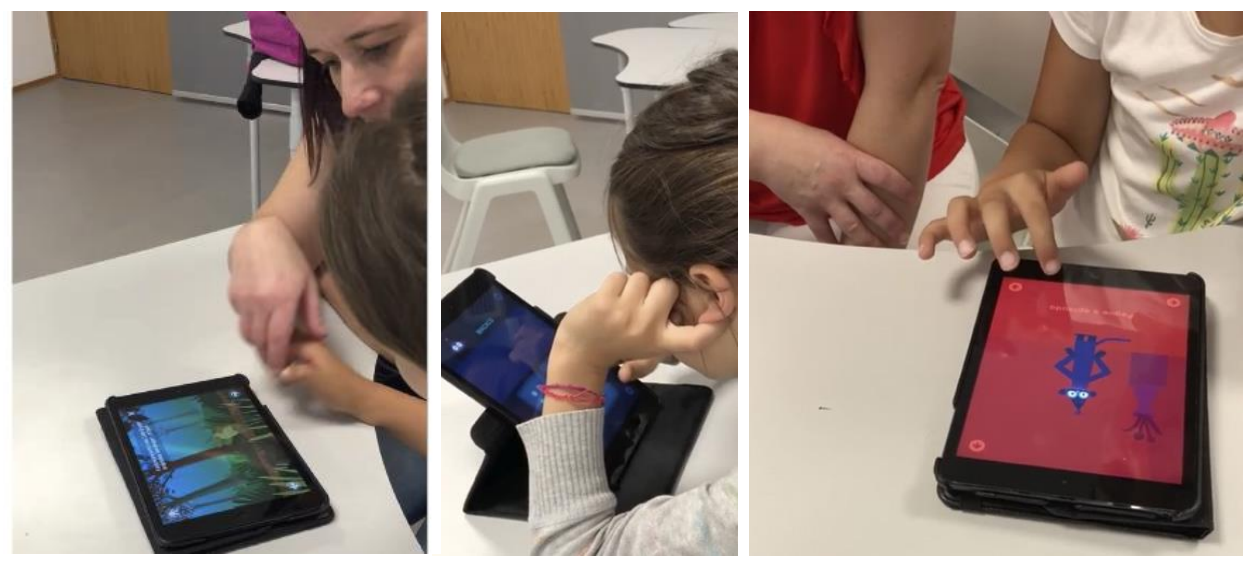

Fonte: Autoria própria (2018).

A pesquisa iniciou com um questionário de hábitos de leitura aos pais. Em seguida, pais e crianças foram convidados a ler ao seu modo cada um dos três aplicativos, sem qualquer intervenção do pesquisador, que coletava os dados na forma de notas e gravação de vídeos. Cada sessão de leitura durou cerca de 20 minutos.

\section{DISCUSSÃO E RESULTADOS DA AVALIAÇÃO DAS INTERFACES PELAS DÍADES DE LEITORES}

Quando questionados, os seis pais participantes disseram ter smartphones, tablets e computadores em casa. O tablet é o dispositivo mais usado pelos seus filhos, aproximadamente uma hora por dia. Quanto aos hábitos de leitura, apenas dois pais afirmaram ler livros diariamente com os filhos, outros dois leem uma vez por semana, enquanto os demais não têm esse hábito. Do total de seis pais, apenas dois já leram apps com seus filhos, enquanto os outros responderam que não sabiam como encontrar e usar aplicativos literários.

Durante as dezoito sessões foi observado que as crianças tomam o controle interativo do livro digital, segurando o dispositivo tablet, inclusive estimuladas pelos pais que ocupam um papel de mediação geralmente menos ativa, monitorando a atividade e só participando mais efetivamente da leitura quando a criança solicita ou se percebem alguma dificuldade ou erro cometido durante a leitura ou interação. Ou seja, apesar de nenhum dos livros aplicativos apresentar um projeto gráfico que inviabiliza a leitura mediada, também não há nenhum recurso nas interfaces gráficas que especialmente incentive a presença de mediadores.

No geral os aplicativos não ofereceram problemas de legibilidade dos textos, o que indica tamanhos, cores e estilos dos caracteres apropriados à leitura da criança e do adulto. Também, os hotspots, mesmo aqueles com áreas menores na forma de botões de navegação, estavam adequados ao toque das crianças. 
Contudo, metade das duplas tiveram a leitura interrompida por problemas de proximidade entre hotspots no app Quanto Bumbum! (Ver fig. 4 - esquerda): quando os leitores tentavam interagir com os passarinhos - no canto superior esquerdo da página -, acabavam acidentalmente acionando o botão home, sobreposto logo acima, que os direcionou à página inicial do livro. O que acarretou que os leitores precisassem reiniciar a leitura. Problema que se intensificou ainda mais devido ao efeito de transição "tela preta" entre páginas que, por gerar um carregamento das páginas é demorado devido aos vídeos longos, fez com que os leitores frequentemente acreditassem que o aparelho tablet havia desligado. Estas interrupções comprometeram muito o fluxo e, por consequência, prejudicaram a experiência de leitura deste aplicativo.

As pistas gráficas do app Quanto bumbum! demonstraram-se, exceto pelo problema supracitado, bem-sucedidas para informar aos leitores onde e quando interagir com as animações. Já no app Marina está do Contra, por demorarem muito a aparecer as pistas de interação sobre a interface, ocasionaram que duas das seis crianças sequer interagissem com as animações durante toda a leitura e outras duas só percebessem estas interações ao meio da história, comprometendo a experiência multimídia. Já o app Macaco de Chapéu, devido à narrativa instrucional, tanto do texto verbal quanto das animações em que o Macaco indica onde tocar na tela, beneficiou uma leitura interativa sem problemas a todas as díades.

Quanto aos botões de navegação, não houve problemas de compreensão daqueles apenas iconográficos, se comparados aqueles acompanhados de descritivos verbais, demonstrando que a presença de textos é desnecessária desde que os ícones dos botões preconizem affordances de suas funções. Do contrário podem comprometer a usabilidade e a leitura, como aconteceu em todas as sessões de leitura de Macaco de Chapéu, quando os leitores queriam avançar a página e erroneamente selecionavam o botão home, devido ao ícone de seta similar ao de navegação entre páginas (reveja a fig. 3), voltando à página inicial do livro ao invés de continuar a leitura.

Interações complexas demandam, como observado, avisos instrucionais para orientar os leitores e mediadores como realizá-las. Apesar das díades terem normalmente desconsiderado a página de instruções iniciais do app Marina está do contra (fig. 4 - direita), não tiveram problemas de interação devido à presença constante de instruções animadas em cada página carregada invertida, relembrando às crianças a virar o dispositivo tablet para lê-la. Porém, este recurso interativo repetitivo, ocorria em todas as páginas do app, e por isso, com a presença também constante de instruções, tornou a leitura enfadonha e previsível para as crianças que, mesmo antes de avançar as páginas, giravam o tablet para contornar esse recurso interativo, percebido então como um contratempo.

Após as três sessões com cada dupla foi observado um aumento de familiaridade das crianças leitoras e seus pais mediadores com a interface dos apps e com os DIMs, como também maior entrosamento entre si. Inclusive, os pais relataram na última sessão que gostaram muito de realizar as leituras e que pretendiam continuar lendo livros digitais com seus filhos em casa, alguns deles solicitaram ao pesquisador indicações de novos títulos que preferencialmente oferecessem a opção de leitura no idioma inglês, o que demonstra que os pais viram também nos aplicativos oportunidades para a aprendizagem infantil de novas línguas. 


\section{CONSIDERAÇÕES FINAIS}

Este estudo teve por intenção avaliar as interfaces gráficas de aplicativos de literatura para a infância, para isso foram mapeadas as interfaces de uma amostra de três apps comerciais e avaliadas suas falhas e êxitos por meio de sessões de leitura mediada com crianças e seus pais. Este processo permitiu não apenas constatar a presença de falhas e soluções no design gráfico dos aplicativos, como também proporcionou operacionalizar e aperfeiçoar o Mapa das Interfaces Multimodais de Livros Infantis para DIMs como uma ferramenta de análise.

Apesar de muitas famílias, hoje em dia, possuírem dispositivos eletrônicos e liberarem o uso diário aos seus filhos, os pais não sabem onde e como encontrar e como selecionar e usar aplicativos literários. Isso se deve também, de acordo com relato dos participantes, à dificuldade de acesso e complexidade de pesquisas oferecidas pelas lojas virtuais. Também, é importante reiterar que aplicativos literários comerciais dificilmente apresentam recursos que demandam ou estimulam a presença de mediadores, afastando ainda mais os pais da leitura digital exercida pelas crianças.

A verificação com crianças e mediadores permitiu reconhecer problemas e soluções bem-sucedidas que permitem inferir recomendações para o design da interface gráfica de apps literários. Os resultados evidenciam que áreas interativas distintas precisam estar adequadamente afastadas entre si, apropriadamente representadas por affordances que forneçam informações compreensíveis, tanto aos leitores nativos-digitais - crianças - como aos mediadores - pais - que migram da literatura impressa. Por isso, pistas de interação na forma de animações sobrepostas à interface gráfica são importantes para avisar onde interagir com elementos da história, contudo a frequência com que aparecem deve ser bem dosada, para que não atrapalhem o fluxo de leitura pelo excesso ou, pela demora, ocasionem que recursos interativos e multimídia sejam desapercebidos.

Interações complexas demandam explicações ao leitor de como este deve interagir com a interface ou, muitas vezes, com o dispositivo, e são melhor percebidas na forma de animações instrucionais preferencialmente aplicadas junto às páginas que demandam as ações interativas, isso porque as páginas instrucionais que antecedem a história tendem a ser desconsideradas ou esquecidas durante a leitura. É, também, importante a inclusão de sumário interativo nos apps, pois dão maior controle e autonomia aos leitores para retomar leituras interrompidas ou revisitar facilmente páginas específicas. E deve haver cuidado com excesso e repetição de hotspots ou outros mecanismos de interação, porque ao invés de engajar a leitura, podem burocratizá-la ou torná-la enfadonha.

Por fim, são limitações deste estudo o tamanho reduzido da amostra de apps literários e de leitores, devido também os esforços individuais do pesquisador. Por outro lado, as amostras reduzidas permitiram-no acompanhar integralmente e mais a fundo todas as etapas da pesquisa, desde a coleta à análise de dados, o que proporcionou maior detalhamento e congruência do processo de pesquisa. As contribuições apresentadas, na forma de resultados de avaliações podem servir como indícios para nortear designers, produtores, mediadores e pesquisadores de literatura digital para a infância, o que eventualmente pode beneficiar futuras produções literárias, pesquisas e novas abordagens de mediação de livros digitais para crianças. 


\title{
Read Interfaces: evaluating graphic interfaces of literature apps for children
}

\begin{abstract}
Nowadays mobile interaction devices, such as tablets and mobile phones, as wel applications (apps) are very popular on children's daily lives. However, there is still resistance from parents and educators to select and use children's digital books due to their lack of knowledge and unfamiliarity to mediation and interaction with digital interfaces, which is most critical due to an abundance of problematic comercial apps. Based mainly on theories and studies of literature for children in the digital context, and continuing previous studies done through the Interaction Design bias, this research aims to evaluate graphic interfaces of literary apps for children. Firstly, in this article, a descriptive analysis of three commercial apps is performed. Next, is performed an observation analysis of mediated reading of these apps by six parent-child dyads, with focus on children 6-to-8 years old whe demand mediation to read. As a result, successes and inconsistencies aspects are indentified in the design of the graphic interfaces of the three apps. That can readily contribute to designers, editors and also serve to researchers, parents and educators for a more careful and consistent selection and literary mediation approach with children's digital children.
\end{abstract}

KEYWORDS: Children's digital book. Electronic book. Interaction Design. Mediated Reading. 


\section{AGRADECIMENTOS}

Agradeço ao apoio do CNPq, na modalidade de bolsa de doutorado sanduíche no exterior realizada na Universidade do Mingo, Portugal (processo 206788 / 20177). Também às crianças e aos seus pais pelas valiosas contribuições e ao diretor e aos professores da Escola Básica de Gualtar, Braga - Portugal, onde as sessões de leitura foram realizadas.

\section{NOTAS}

${ }^{1}$ In other words, the success of hypermedia elec- tronic storybooks may depend critically on a variety of pedagogical and design factors as well as on the maturity of executive functions and comprehension skills that the child possesses" (BUS; TAKACS, KEGEL; 2015, p. 89).

\section{REFERÊNCIAS}

AL-YAQOUT, G., NIKOLAJEVA, M. Re-conceptualising picturebook theory in the digital age. Nordic Journal of ChildLit Aesthetics, Oslo, Noruega, v. 6, n.1, 26971, 2015.

BUS, A. G., TAKACS, Z. K., KEGEL, C. A. T. Affordances and limitations of electronic storybooks for young children's emergent literacy. Developmental Review, 35, pp. 79-97, 2015.

CAHILL, M., MCGILL-FRANZEN, A. Selecting “app”ealing and “app"ropriate book apps for beginning readers. Reading Teacher, v. 67, n. 1, pp. 30-39, 2013.

CARDOSO, E., FREDERICO, A. Literatura digital dentro e fora da escola: a mediação da experiência estética na infância. Leitura: Teoria \& Prática, Campinas, São Paulo, v.37, n.75, p.19-38, 2019.

EDITORA CAIXOTE. Marina está do Contra, versão 1.1.5, 2017. Disponível em: <https://apps.apple.com/pt/app/marina-est\%C3\%A1-docontra/id1171371653>. Acesso em: 15 mar. 2019

EDITORA CAIXOTE. Quanto bumbum! versão 1.4.1, 2016. Acessado em: 15 mar. 2019.

FOLLMER, S., BALLAGAS, R., RAFFLE, H., SPASOJEVIC, M., ISHII, H. People in books: Using a FlashCam to become part of an interactive 
FOX \& SHEEP. (2014). Macaco de Chapéu, versão 1.9. Acessado em 15 mar. 2019. Disponível em: <https://apps.apple.com/pt/app/macaco-chapeufor-kids-to/id904565251> Acesso em: 10 ago. 2019.

HØYRUP, H. Towards a Connective Ethnography of Children's Literature and Digital Media: The New Media Encounter. In: NODELMAN, P., HAMER, N.; REIMER, M. More Words About Pictures: Current Research on Picture Books and Visual/Verbal Texts for Young People, ed. New York \& London: Routledge, 2017. p. 81-99.

JAVORSKY, K; TRAININ, G. Teaching Young Readers to Navigate a Digital Story When Rules Keep Changing. Reading Teacher, v. 67, n.8, p. 606-618, 2014.

KAO, G. Y.-M., TSAI, C.-C., LIU, C.-Y., YANG, C.-H. The effects of high/low interactive electronic storybooks on elementary school students' reading motivation, story comprehension and chromatics concepts.

Computers and Education, n. 100, p. 56-70, 2016.

KAMYSZ, K., WICHROWSKI, M. A little goat builds the world: an interactive children story for tablets. Lecture Notes in Computer Science, 8832, p. 228-231, 2014.

KUCIRKOVA, N. An integrative framework for studying, designing and conceptualising interactivity in children's digital books. British Educational Research Journal, v. 43, n. 6, p. 1168-1185, dez. 2017

LIMA, G. Da Página à Tela: Apontamentos sobre a Leitura da Literatura Infantil na Cultura Digital. Revista Brasileira de Alfabetização, Belo Horizonte, MG, v. 1, n. 8, p. 136-156, jul./dez. 2018

MENEGAZZI, D. Design de hotspots: diretrizes para o design de interação de livros infantis para dispositivos de interação móvel. Tese (Doutorado em Design) - Setor de Artes, Comunicação e Design da Universidade Federal do Paraná, Curitiba, 2020.

SYLLA, C., PADOVANI, S. Rethinking the Design of Hotspots in Children's Digital Picturebooks: Insights from an Exploratory Study. In: SYLLA C., IURGEL I. (eds.) Lecture Notes of the Institute for Computer Sciences, Social Informatics and Telecommunications Engineering (307). Springer, Cham (2020). 
- Modos de Ler, Interagir e Mediar com Aplicativos de Histórias para Crianças. In: LIMA, R. S., AMORIM, A. M., CABALA, F. (Orgs.) Anais do XVI Congresso Internacional Abralic: Circulação, tramas \& sentidos na Literatura. Universidade de Brasília (UnB), Jul. 2019.

. O Design de interfaces de livros infantis apps: uma revisão das características e recomendações. Textura, Canoas v. 20 n. 43 p. 215-239, maio/ago 2018.

., SYLLA, C., PADOVANI, S. Hotspots em livros infantis digitais: um estudo de classificação das funções. Proceedings of 2nd International Conference on Design and Digital Communication, p. 45 - 56, 2018a.

SYLLA, C., PADOVANI, S. A Preliminary Study of Interactivity on Visual Narrative in Children's Story Apps. Proceedings of 6th International Conference on Illustration and Animation, IPCA Instituto Politécnico do Cávado e do Ave, Barcelos, PT, jul. 2018, pp. 636 644, $2018 b$.

PADOVANI, S. A Linguagem Visual no e-Book Infantil: Análise do Livro app "Wuwu \& Co.” Educação Gráfica, v. 21 n. 02, p. 37-51, 2017

MORAES, E., FREDERICO, A. Literatura digital dentro e fora da escola: a mediação da experiência estética na infância. Leitura: Teoria \& Prática, Campinas, São Paulo, v.37, n.75, p.19-38, 2019.

MORGAN, H. Multimodal Children's Ebooks Help Young Learners in Reading. Early Childhood Education Journal, v. 41, n. 6, p. 477-483, nov. 2013.

PNAIC 2017. Pacto Nacional pela Alfabetização na Idade Certa.

Documento Orientador. Ministério da Educação Secretaria de Educação Básica, Brasília, DF, 2017. Disponível em 〈https://goo.gl/YDBTGQ> Acesso em: 12 ago, 2019.

PRÊMIO JABUTI. CBL Disponível em <http://premiojabuti.com.br> . Acesso em: 10 de ago. 2019.

SARGEANT, B. What is an ebook? What is a Book App? And Why Should We Care? An Analysis of Contemporary Digital Picture Books. n. 4, p. 454-466, 2015. 
SERAFINI, F., KACHORSKY, D., AGUILERA, E. Picture Books in the Digital Age. Reading Teacher, v.69, n. 5, p. 509-5012, 2016.

TEIXEIRA, D. J., GONÇALVES, B. A hipermídia como expressão do conteúdo dramático em narrativa digital interativa: uma análise em livro digital interativo infantil. Revista Brasileira de Design da Informação, São Paulo, v. 12, n.1 p.1-15, 2015

YUILL, N., MARTIN, A. F. Curling Up with a Good E-Book: MotherChild Shared Story Reading on Screen or Paper Affects Embodied Interaction and Warmth. Frontiers in Psychology, v. 7, p. 1-12, dez. 2016.

Recebido: 20 fev. 2020

Aprovado: 29 mar. 2020

DOI: $10.3895 / \mathrm{rl} . v 22 n 36.11661$

Como citar: MENEGAZZI, Douglas. Ler Interfaces: Avaliação das Interfaces Gráficas de Aplicativos de Literatura para a Infância. R. Letras, Curitiba, v. 22, n. 36, p. 21-35, mar. 2020. Disponível em: $<$ https://periodicos.utfpr.edu.br/rl>. Acesso em: XXX.

Direito autoral: Este artigo está licenciado sob os termos da Licença Creative Commons-Atribuição 4.0 Internacional. 